\title{
Phase II and UGTIAI genotype study of irinotecan dose escalation as salvage therapy for advanced gastric cancer
}

\author{
J-C Jo',4, J-L Lee', ${ }^{1,4}$ M-H Ryu', HM Chang', M Kim², HJ Lee', H-S Kim³, J-G Shin ${ }^{3}$, T-W Kim' and Y-K Kang*,I \\ 'Department of Oncology, Asan Medical Center, University of Ulsan College of Medicine, 88 Olympic-ro 43-gil, Songpa-gu, Seoul I38-736, Korea; \\ ${ }^{2}$ Department of Pharmacy, Asan Medical Center, University of Ulsan College of Medicine, Seoul 138-736, Korea; ${ }^{3}$ Department of Pharmacology \\ and Pharmacogenomics Research Center, Inje University College of Medicine, Busan 633-165, Korea
}

BACKGROUND: To assess the efficacy and safety of individualised dose optimisation of irinotecan monotherapy as salvage treatment for advanced gastric cancer (AGC).

METHODS: A total of 43 patients were enrolled. Intravenous irinotecan $\left(350 \mathrm{mg} \mathrm{m}^{-2}\right)$ was administered every 3 weeks. The dose was increased $\left(425 \mathrm{mg} \mathrm{m}^{-2}\right.$ and $\left.500 \mathrm{mg} \mathrm{m}^{-2}\right)$ or decreased $\left(250 \mathrm{mg} \mathrm{m}^{-2}\right)$ depending on patient tolerance. UGTIAI genotypes were determined by direct sequencing of genomic DNA extracted from peripheral blood.

RESULTS: A total of 183 cycles of irinotecan were administered, with a median of four cycles per patient. The overall response rate was $9.3 \%$, and the disease control rate was $62.8 \%$. Median time to disease progression was 2.8 months, and median overall survival was 8.0 months. Grade 3-4 neutropenia was the most common toxicity (53.5\%), and febrile neutropenia was the least common toxicity (4.6\%). Compared with defective allele groups, UGTIAI *I/*I was associated with a lower incidence of grade 3-4 neutropenia during the first cycle $(P=0.018)$.

CONCLUSION: Individualised irinotecan dose escalation based on patient tolerance was not associated with increased toxicity and shows modest activity as salvage chemotherapy for AGC. The role of UGTIAI genotype in clinical toxicity requires further evaluation.

British Journal of Cancer (2012) 106, I59|-1597. doi:I0.1038/bjc.2012.143 www.bjcancer.com

Published online 19 April 2012

(c) 2012 Cancer Research UK

Keywords: gastric cancer; irinotecan; salvage therapy; chemotherapy; UDP-glucuronosyltransferase; genotype

Gastric cancer is the fourth most common type of cancer and the second most common cause of cancer deaths world-wide (Parkin et al, 2005). Although improvements in early diagnosis have increased the number of curative resections, many patients present with locally advanced unresectable lesions or distant metastases at the initial diagnosis. Even after complete resection, local and distant relapse are common. In these patients, palliative chemotherapy can improve the length and quality of life compared with the best supportive care alone (Murad et al, 1993; Pyrhonen et al, 1995; Glimelius et al, 1997).

Fluoropyrimidine and platinum combination chemotherapy (with or without anthracycline) is a commonly used first-line treatment for advanced gastric cancer (AGC) (Kim et al, 1993, 2002; Webb et al, 1997; Vanhoefer et al, 2000; Koizumi et al, 2003; Kang et al, 2010). Our group examined the efficacy and safety of capecitabine plus cisplatin (XP) (Kim et al, 2002) and XP with docetaxel regimens (Kang et al, 2011). Results from the REAL-2 and ML17032 trials indicate that capecitabine could replace infusional 5-fluoracil (5-FU), demonstrating equal efficacy with the advantage of convenience (Cunningham et al, 2008; Kang et al, 2009).

No standard chemotherapy regimen for AGC currently exists, but more patients are given fluoropyrimidine, a platinum compound,

\footnotetext{
*Correspondence: Dr Y-K Kang; E-mail: ykkang@amc.seoul.kr

${ }^{4}$ These authors contributed equally to this work.

Revised 28 February 2012; accepted 21 March 2012; published online 19 April 2012
}

and a taxane (concomitantly or sequentially). However, about $50 \%$ of gastric cancers do not respond to chemotherapy. Most patients who achieve response eventually experience disease progression, with unsatisfactory treatment results. Thus, there is an urgent need for an effective and less toxic regimen for patients with AGC who do not respond to a chemotherapy regimen consisting of fluoropyrimidine, a platinum compound, and a taxane.

Irinotecan is an S-phase-specific, semisynthetic derivative of camptothecin that interferes with DNA replication and cell division by inhibiting topoisomerase I. Its mechanism of action differs from those of fluoropyrimidines, platinum compounds, and taxanes. Pharmacokinetic studies of irinotecan have reported large variations among individuals, as assessed by area under the concentration-time curves of the active metabolite 7-ethyl-10hydroxycamptothecin $(\mathrm{SN}-38)$ and the inactive glucuronide metabolite (SN-38G), which is conjugated to UDP-glucuronosyltransferase (UGT; Gupta et al, 1994). UGT1A1 is believed to be the isoform primarily responsible for SN-38G formation, and interindividual variability in $\mathrm{SN}-38 \mathrm{G}$ formation is due to various UGT1A1 genotypes (Iyer et al, 1998). A phase I trial by Abigerges et al (1995) reported all objective responses at dose levels above $350 \mathrm{mg} \mathrm{m}^{-2}$ irinotecan. One patient responded to a dose of $260 \mathrm{mg} \mathrm{m}^{-2}$, and one patient with progressive gastric cancer treated with $350 \mathrm{mg} \mathrm{m}^{-2}$ irinotecan achieved partial response with $600 \mathrm{mg} \mathrm{m}^{-2}$.

We conducted a prospective phase II study of irinotecan monotherapy for the treatment of patients with AGC who 
previously failed chemotherapy consisting of a fluoropyrimidine, a platinum compound, and a taxane. We used a patient-specific dose escalation scheme based on tolerance during the preceding cycle and evaluated the relationship between UGT1A1 genotype with irinotecan toxicity.

\section{PATIENTS AND METHODS}

\section{Patients}

All enrolled patients received a diagnosis of advanced, unresectable, histologically confirmed adenocarcinoma of the stomach. The inclusion criteria were as follows: (i) 18 to 65 years old; (ii) Eastern Cooperative Oncology Group performance status of 0 or 1 ; (iii) prior treatment with chemotherapy consisting of a fluoropyrimidine (5-FU, capecitabine, doxifluridine, S1, or tegafur-uracil), a platinum compound (cisplatin or oxaliplatin), and a taxane (paclitaxel or docetaxel); (iv) presence of measurable lesion(s) based on criteria of the Response Evaluation Criteria in Solid Tumors (RECIST, version 1.0); (v) no previous radiotherapy; (vi) estimated life expectancy $>3$ months; (vii) adequate bone marrow function (leukocyte count $\geqslant 4000 \mu \mathrm{l}^{-1}$, absolute neutrophil count $\geqslant 1500 \mu \mathrm{l}^{-1}$, haemoglobin $\geqslant 9.0 \mathrm{~g} \mathrm{dl}^{-1}$, and platelet count $\geqslant 100000 \mu \mathrm{l}^{-1}$ ); and (viii) adequate renal and hepatic function (serum creatinine $<1.5 \mathrm{mg} \mathrm{dl}^{-1}$, bilirubin $<1.2 \mathrm{mg} \mathrm{dl}^{-1}$, and serum transaminases (aspartate transaminase and alanine transaminase) less than three times the upper normal limit and less than five times the upper normal limit for patients with liver metastases). Patients were excluded if they had brain metastases, significant gastrointestinal bleeding or obstruction, or a serious comorbid condition; concomitantly used any drug that was a possible substrate, inducer, or inhibitor of UGT1A1; or lacked the ability to comply with the requirements of the protocol. All patients provided written informed consent, and the Asan Medical Centre institutional review board approved this study (approval No. 2005-0215).

\section{Treatment protocol and dose adjustment}

Patients received irinotecan at a starting dose of $350 \mathrm{mg} \mathrm{m}^{-2}$ in $250 \mathrm{ml} 5 \%$ dextrose-water over 90 min every 3 weeks. At the second cycle, the dosage was decreased or increased depending on individual patient tolerance in the preceding cycle. In the absence of moderate toxicity (grade 2 or worse non-haematological toxicity (except alopecia) or grade 3 or worse haematological toxicity (except anaemia)), the dose was increased to $425 \mathrm{mg} \mathrm{m}^{-2}$ at cycle 2 , and then to $500 \mathrm{mg} \mathrm{m}^{-2}$ at cycle 3 and subsequent cycles. If a patient experienced significant toxicities (grade 3 or worse non-haematological toxicities, grade 4 neutropenia lasting $\geqslant 7$ days, grade 3 thrombocytopenia with bleeding, or grade 4 thrombocytopenia), the dose was reduced to that of the previous cycle and re-escalation of irinotecan was not allowed.

For patients who experienced significant toxicity in the first cycle, irinotecan was reduced to $250 \mathrm{mg} \mathrm{m}^{-2}$ for cycle 2 and every cycle thereafter. Otherwise, irinotecan was maintained at the same dose as the previous cycle. Patients who experienced significant toxicity despite dose reduction to $250 \mathrm{mg} \mathrm{m}^{-2}$ were withdrawn from the study. A chemotherapy cycle was delayed if the granulocyte count was $<1500 \mu \mathrm{l}^{-1}$ or if the platelet count did not return to a minimum of $100000 \mu \mathrm{l}^{-1}$ on the day of infusion. Other non-haematological toxicities (except alopecia) were required to be grade 1 or better prior to cycle initiation. A treatment delay of up to 1 week was permitted without dose modification. If treatment was delayed more than 1 week, the dose for the following cycle was reduced by 1 dose level; if treatment was delayed by more than 3 weeks, the patient was withdrawn from the study. Colony-stimulating factors (e.g., G-CSF, GM-CSF) and antibiotics were not given prophylactically or to treat uncomplicated neutropenia. Irinotecan treatment was administered for a maximum of nine cycles unless there was disease progression, withdrawal of consent, or unacceptable toxicity.

\section{Efficacy and safety assessment}

Tumour response was evaluated every two treatment cycles according to the RECIST criteria (version 1.0). The imaging technique used at baseline was used at subsequent examinations, and the investigators for this trial assessed response to chemotherapy. A patient was considered eligible for tumour assessment if he or she received at least two cycles of chemotherapy or experienced rapid tumour progression (per-protocol population). For intention-to-treat (ITT) analysis, those who failed to return to the clinic for any reason after receiving at least one cycle of chemotherapy were included in the denominator to calculate the response rate (RR). Toxicity was evaluated according to the National Cancer Institute Common Toxicity Criteria for Adverse Events scale (version 3.0).

\section{UGT1A1 genetic assay}

Genomic DNA was extracted from blood leukocytes using a DNA Blood Mini Kit (Qiagen, Hilden, Germany). The first exon and flanking region of the human UGT1A1 gene were amplified by polymerase chain reaction (PCR) using the following primers: forward 5'-CATGATACAAGTGAGCAGGC-3' and reverse $5^{\prime}$-GGGG CTAGTTAATCGATCCA- $3^{\prime}$. The $30-\mu$ l reaction mixture contained $1 \times$ buffer, $0.2 \mathrm{mmoll}^{-1}$ dNTPs, 50-100 ng genomic DNA, $0.5 \mu \mathrm{moll}^{-1}$ primers, and 1 unit Taq DNA polymerase (TaKaRa, Shiga, Japan). After a 3-min hot start at $94{ }^{\circ} \mathrm{C}, 30$ cycles were performed on a GeneAmp PCR 9700 system (PerkinElmer, Norwalk, CT, USA). The amplified DNA product was purified using QIAquick columns (Qiagen) according to the manufacturer's recommendations. Nucleotide sequences of the PCR products were determined by an automated sequencer (ABI3130XL, Applied Biosystems, Foster City, CA, USA).

Genotyping of $-3279 \mathrm{~T}>\mathrm{G}$ (UGT1A $1^{\star} 60$ allelic variant) was determined by pyrosequencing. The 227-bp fragment containing $-3279 \mathrm{~T}>\mathrm{G}$ was amplified using the following primers: forward $5^{\prime}$-TTAACCAAAGAACATTCTAACGG- $3^{\prime}$ and reverse $5^{\prime}$-biotin-TGCTGTTCCCCAAACTTC- $3^{\prime}$. The PCR mixture included $0.2 \mathrm{mmoll}^{-1}$ dNTPs, $0.2 \mu \mathrm{moll}^{-1}$ each primer, 150-ng human genomic DNA, and $2 \mathrm{U}$ Taq polymerase (TaKaRa) in a $20-\mu \mathrm{l}$ volume. After an initial denaturation at $95^{\circ} \mathrm{C}$ for $5 \mathrm{~min}$, amplification was carried out with 30 cycles of denaturation at $95^{\circ} \mathrm{C}$ for $30 \mathrm{~s}$, annealing at $55^{\circ} \mathrm{C}$, and extension at $72^{\circ} \mathrm{C}$ for $30 \mathrm{~s}$. Sepharose beads ( $40 \mu \mathrm{l}$ per well; Streptavidin Sepharose High Performance, Amersham Biosciences, Uppsala, Sweden) were diluted with binding buffer, mixed with the PCR product, transferred to a filter plate, and incubated for $10 \mathrm{~min}$ at room temperature on a shaking device with continuous mixing. Then, the liquid was removed by vacuum filtration (Multiscreen Resist Vacuum Manifold, Billerica, MA, USA), and the double-stranded DNA was denatured in $0.5 \mathrm{moll}^{-1} \mathrm{NaOH}$. The immobilised template was treated for $5 \mathrm{~s}$ each with $70 \%$ ethanol, denaturation buffer, and then washing buffer, and transferred to a PSQ 96 plate (Biotage, Uppsala, Sweden). The washed template was resuspended in annealing buffer $\left(20 \mathrm{mmoll}^{-1}\right.$ Tris-acetate, $\left.\mathrm{pH} 7.6\right)$ that contained the sequencing primers $\left(5^{\prime}\right.$-CCAAGGGTAGAGTTCAG- $\left.3^{\prime}\right)$. Primer and template mixtures were heated at $90{ }^{\circ} \mathrm{C}$ for $3 \mathrm{~min}$, and the reactions were allowed to cool to room temperature. The resulting mixture was analysed on a PSQ96MA pyrosequencer (Biotage).

\section{Statistical analysis}

Overall RR was the primary end point of this study. Simon's optimal two-stage design was used to test the null hypothesis 
$\left(P_{0} \leqslant 0.05\right) v s$ the alternative hypothesis $\left(P_{1} \geqslant 0.2\right)$. The first stage required that at least 1 patient in 10 had a confirmed response (with $\alpha=0.05$ and $\beta=0.2$ ) before the second stage began. The second stage required the treatment of an additional 19 assessable patients. If four or more patients achieved a confirmed response, then the primary end point would be met.

The TTP was measured from the first day of irinotecan treatment until disease progression was noted, and OS was measured from the first day of irinotecan treatment until death from any cause. Kaplan-Meier estimates were used to analyse all time-event variables, and curves were compared by the log-rank test. Patient characteristics and toxicities were evaluated by descriptive methods.

If the phase II part of the study indicated that our regimen was effective, then we planned to carry out a prospective investigation of the relationship between UGT1A1 diplotype and the severity of neutropenia during the first cycle. We compared the percentage of grade 3-4 neutropenia in patients carrying the ${ }^{\star} 1 /{ }^{\star} 1$ diplotype with those of patients carrying a defective allele using the Fisher's exact test. If we assume that $90 \%$ of patients with the ${ }^{*} 1 /{ }^{\star} 1$ diplotype will not experience grade 3-4 neutropenia, and $50 \%$ of patients with defective alleles $\left({ }^{\star} 28,{ }^{\star} 6\right.$, or ${ }^{\star} 60$ ) will not experience a grade 3-4 neutropenia, then a sample size of 40 gives $80 \%$ power (at $\alpha=0.1$ ) to detect a difference based on the known frequency of the UGT1A $1{ }^{\star} 1 /{ }^{\star} 1$ diplotype in the Korean population $(30 \%)$ (Ki et al, 2003). SPSS for Windows (SPSS Inc., Chicago, IL, USA) was used for all statistical analyses.

\section{RESULTS}

\section{Patient characteristics}

From September 2005 to June 2007, 43 eligible patients who were previously exposed to a fluoropyrimidine, a platinum compound, and a taxane were enrolled (Table 1). The median age was 51 years (range: 31-64 years), 15 patients underwent curative gastrectomy, and 11 patients received adjuvant chemotherapy including mitomycin C and oral 5-FU. Most patients (77\%) had two or more sites of metastasis. In all, 37 patients $(86 \%)$ received secondline chemotherapy, and docetaxel monotherapy was the most common second-line regimen (26 out of $37,70 \%$ ). A total of 32 patients $(74 \%)$ had disease progression during previous chemotherapy, and 41 patients (95\%) had disease progression within 6 months after withdrawal of the previous chemotherapy regimen. The median TTP (from day 1 of the first cycle of the previous chemotherapy) was 2.8 months (range: 1.2-12.8 months). The median treatment-free interval (TFI) was 31 days (range: 17 days7.2 months).

\section{Drug delivery}

The median number of chemotherapy cycles was four (range: 1-9; total: 183 cycles), with $26.3 \%$ of cycles delivered at $250 \mathrm{mg} \mathrm{m}^{-2}$, $55.6 \%$ at $350 \mathrm{mg} \mathrm{m}^{-2}, 12.8 \%$ at $425 \mathrm{mg} \mathrm{m}^{-2}$, and $5.0 \%$ at $500 \mathrm{mg} \mathrm{m}^{-2}$. Five patients did not proceed to the second cycle because of patient refusal $(n=2)$ or disease progression $(n=3)$. Overall, 10 of the 38 patients $(26.3 \%)$ who received more than one cycle of chemotherapy received a dose of $425 \mathrm{mg} \mathrm{m}^{-2}$ at least once, and 3 of the 38 patients $(7.9 \%)$ received a dose of $500 \mathrm{mg} \mathrm{m}^{-2}$. The irinotecan dose was reduced to $250 \mathrm{mg} \mathrm{m}^{-2}$ for 9 of these 38 patients (23.7\%). Treatment was delayed for 11 patients $(25.6 \%)$ and in 23 cycles (12.6\%). Dose reduction occurred for 12 patients $(27.9 \%)$ and in 48 cycles $(26.2 \%)$. Reasons for dose reduction were fatigue (83.3\%), granulocytopenia (14.6\%), and diarrhoea $(6.3 \%)$. The most frequent reason for dose delay was neutropenia (63.6\%). The median dose intensity per patient was $116.7 \mathrm{mg} \mathrm{m}^{-2}$ per week (range: 71.2-152.6), and the mean dose of irinotecan at each cycle
Table I Baseline clinicopathological characteristics of patients with advanced gastric cancer

\begin{tabular}{|c|c|c|}
\hline & No. of patients & $\%$ \\
\hline $\begin{array}{l}\text { Total no. } \\
\text { Age, years (median, range) }\end{array}$ & $\begin{array}{c}43 \\
51(31-64)\end{array}$ & 100 \\
\hline $\begin{array}{l}\text { Gender } \\
\text { Male } \\
\text { Female }\end{array}$ & $\begin{array}{c}35 \\
8\end{array}$ & $\begin{array}{l}81.4 \\
18.6\end{array}$ \\
\hline $\begin{array}{l}\text { ECOG performance status } \\
0 \\
1\end{array}$ & $\begin{array}{l}17 \\
26\end{array}$ & $\begin{array}{l}39.5 \\
60.5\end{array}$ \\
\hline $\begin{array}{l}\text { Histology } \\
\text { Well/moderately differentiated } \\
\text { Poorly differentiated or signet-ring cell type } \\
\text { Unknown }\end{array}$ & $\begin{array}{l}15 \\
21 \\
7\end{array}$ & $\begin{array}{l}34.9 \\
48.9 \\
16.3\end{array}$ \\
\hline $\begin{array}{l}\text { Metastasis sites } \\
\text { Liver } \\
\text { Peritoneum } \\
\text { Distant abdominal lymph nodes } \\
\text { Lung } \\
\text { Bone }\end{array}$ & $\begin{array}{c}22 \\
20 \\
29 \\
4 \\
4\end{array}$ & $\begin{array}{r}51.2 \\
46.5 \\
67.4 \\
9.3 \\
9.3\end{array}$ \\
\hline $\begin{array}{l}\text { No. of metastatic sites } \\
1 \\
2 \\
\geqslant 3\end{array}$ & $\begin{array}{l}10 \\
22 \\
11\end{array}$ & $\begin{array}{l}23.3 \\
51.2 \\
25.6\end{array}$ \\
\hline Prior gastrectomy & 15 & 34.9 \\
\hline $\begin{array}{l}\text { No. of previous treatment lines } \\
\quad \\
2\end{array}$ & $\begin{array}{c}6 \\
37\end{array}$ & $\begin{array}{l}13.9 \\
86.1\end{array}$ \\
\hline $\begin{array}{l}\text { First-line chemotherapy regimen } \\
\quad T \\
\text { FP } \\
\text { FT } \\
\text { TP } \\
\text { FTP }\end{array}$ & $\begin{array}{c}2 \\
26 \\
3 \\
6 \\
6\end{array}$ & $\begin{array}{l}4.6 \\
60.4 \\
7.0 \\
14.0 \\
14.0\end{array}$ \\
\hline
\end{tabular}

Abbreviations: $\mathrm{ECOG}=$ Eastern Cooperative Oncology Group; $\mathrm{T}=$ taxane (docetaxel); $\mathrm{F}=$ fluoropyrimidine (5-FU, capecitabine, or $\mathrm{S}-\mathrm{I}$ ); $\mathrm{P}=$ platinum (cisplatin or oxaliplatin).

was $351.9 \pm 8.7 \mathrm{mg}$ (mean \pm s.e.) during the second cycle $(n=38)$, $347.1 \pm 14.6 \mathrm{mg}$ during the third cycle $(n=26), 350.0 \pm 17.0 \mathrm{mg}$ during the fourth cycle $(n=22), 360.0 \pm 20.5 \mathrm{mg}$ during the fifth cycle $(n=15)$, and $366.0 \pm 21.0 \mathrm{mg}$ during the sixth cycle $(n=14)$.

\section{Efficacy}

Of the first 29 patients enrolled, 3 patients achieved a partial response. Fourteen more patients were subsequently included in the study. Overall, four patients achieved confirmed partial response, resulting in objective RRs of 9.3\% (95\% CI: 0.6-18.0) for the ITT population and 9.8\% (95\% CI: $0.4-18.2)$ for the perprotocol population. The duration of objective response in these four patients was $2.5,2.8,5.8$, and 11.0 months. A total of 23 patients had stable disease, and the overall tumour control rate was $62.8 \%$ for the ITT population. The tumour control rate was $80 \%$ for the 10 patients who received an increased dose at cycle 2, and $67.9 \%$ for the remaining 28 patients. Two patients were not assessable for response because they refused further treatment after the first cycle of chemotherapy. Response to previous chemotherapy was not correlated with response to irinotecan monotherapy $(P=0.537)$.

At a median follow-up time of 18.4 months (95\% CI: 8.7-28.1), the median TTP was 2.8 months (95\% CI: $2.3-3.4$ ), and the median OS was 8.0 months (95\% CI: 6.2-9.8; Figure 1). The TTP and OS were not significantly associated with patient age (age $\leqslant 51$ years 
$v s$ age $>51$ years), sex, histological differentiation, number of metastatic sites, prior response to previous chemotherapy, TTP in the previous chemotherapy (TTP $\leqslant 2.8$ months $v s$ TTP $>2.8$ months), or TFI (TFI $\leqslant 31$ days $v s$ TFI $>31$ days). The median TTP for the 10 patients who received an increased dose at cycle 2 was 4.1 months; the median TTP for the remaining 28 patients was 2.8 months (hazard ratio: $0.91,95 \%$ CI: $0.41-2.04, P=0.833$ ).

\section{Safety}

All 43 patients were evaluable for adverse events. Table 2 shows the patient distribution according to the highest observed toxicity grade and incidence of adverse events per chemotherapy cycle. The most common haematological toxicity was granulocytopenia; grade 3-4 granulocytopenia occurred in 23 patients $(53.5 \%)$ and in $27.5 \%$ of the cycles. Febrile neutropenia was the least common toxicity, developing in two patients $(4.6 \%)$ who were treated successfully with antibiotics and G-CSF, with no recurrence after adequate dose modification. The most common grade 3-4 nonhaematological toxicities were fatigue $(32.6 \%$ of patients; $10.1 \%$ of cycles), nausea (16.3\% of patients; $4.5 \%$ of cycles), vomiting

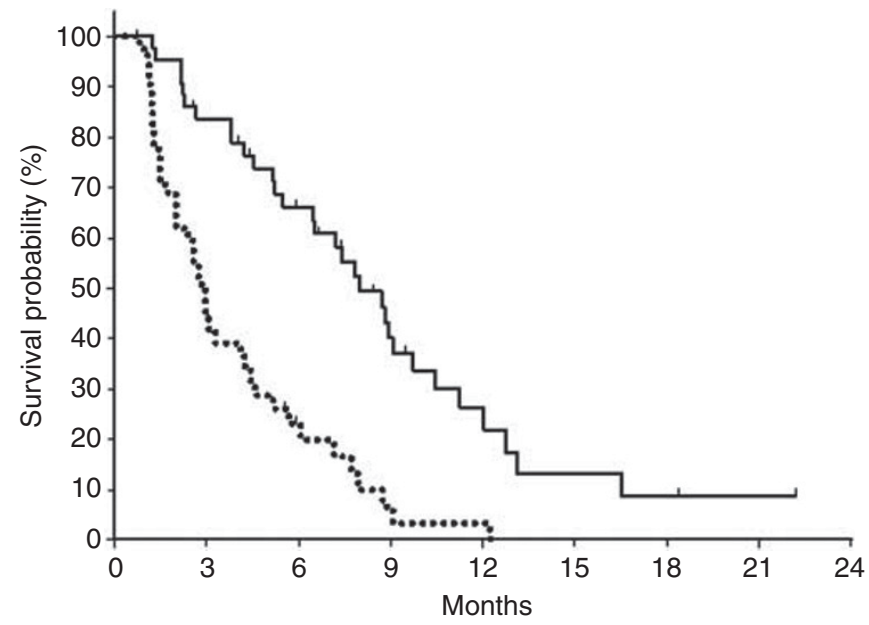

Figure I Time to progression (dotted line) and overall survival (solid line) of patients with advanced gastric cancer $(n=43)$.
(16.3\% of patients; $3.9 \%$ of cycles), and anorexia (14.0\% of patients; $4.5 \%$ of cycles). Severe diarrhoea occurred in only four patients $(9.3 \%)$ and in $2.3 \%$ of cycles. All other toxicities were observed in less than $5 \%$ of patients. No treatment-related deaths were directly attributable to irinotecan chemotherapy. Among the 10 patients who underwent dose escalation from cycle 2, grade 3 or worse granulocytopenia occurred in five patients, vomiting in two patients, and diarrhoea in one patient (Table 3). The prevalence of severe toxicities for patients who underwent irinotecan dose escalation $(n=10)$ did not differ from that of the other patients $(n=28)$

\section{UGT1A1 genotype and allele frequencies}

Table 4 shows the UGT1A1 variants and allele frequencies of the 43 enrolled patients. UGT1A1 allele frequencies were 0.278 for $-3279 \mathrm{~T}>\mathrm{G}\left({ }^{\star} 60\right)$ and 0.222 for $211 \mathrm{G}>\mathrm{A}\left({ }^{*} 6\right)$. This finding

Table 3 Grade 3 or worse toxicity related to irinotecan dose escalation in patients proceeding to the second cycle $(n=38)$

\section{Dose escalation}

\begin{tabular}{lcc} 
Grade 3 or worse & Yes $(\mathbf{n}=\mathbf{l} \mathbf{0})$ & No $(\mathbf{n}=\mathbf{2 8})$ \\
\hline Anaemia & 0 & $5(17.8 \%)$ \\
Leukopenia & $3(30 \%)$ & $9(32.1 \%)$ \\
Neutropenia & $5(50 \%)$ & $15(53.5 \%)$ \\
Thrombocytopenia & 0 & $1(3.5 \%)$ \\
Bleeding & 0 & 0 \\
Febrile neutropenia & 0 & $1(3.5 \%)$ \\
Fatigue & 0 & 10 \\
Anorexia & 0 & $4(14.2 \%)$ \\
Nausea & 0 & $5(17.8 \%)$ \\
Vomiting & $2(20 \%)$ & $2(7.1 \%)$ \\
Stomatitis & 0 & 0 \\
Constipation & 0 & 0 \\
Diarrhoea & $1(10 \%)$ & $2(7.1 \%)$ \\
Abdominal pain & 0 & 0 \\
Transaminitis (ALT) & 0 & $2(7.1 \%)$ \\
Transaminitis (AST) & 0 & $1(3.5 \%)$ \\
Hyperbilirubinemia & 0 & $1(3.5 \%)$ \\
Cholinergic symptoms & 0 & 0 \\
\hline
\end{tabular}

Abbreviations: $\mathrm{ALT}=$ alanine transaminase; $\mathrm{AST}=$ aspartate transaminase.

Table 2 Haematological and non-haematological toxicities associated with irinotecan monotherapy $(n=43)$

\begin{tabular}{|c|c|c|c|c|c|c|c|c|}
\hline \multirow[b]{2}{*}{ Category } & \multicolumn{4}{|c|}{ Grade (no. of patients, \%) } & \multicolumn{4}{|c|}{ Grade (no. of cycles, \%) } \\
\hline & $\mathbf{I}$ & 2 & 3 & 4 & $\mathbf{I}$ & 2 & 3 & 4 \\
\hline Anaemia & $10(23.3)$ & $25(58.1)$ & $3(7.0)$ & $3(7.0)$ & $66(37.1)$ & $72(40.4)$ & $14(7.9)$ & $3(1.7)$ \\
\hline Leukopenia & II (25.6) & II (25.6) & $13(30.2)$ & $2(4.7)$ & $44(24.7)$ & $32(18.0)$ & $24(13.5)$ & $2(1.1)$ \\
\hline Neutropenia & $7(16.3)$ & $8(18.6)$ & $7(16.3)$ & $16(37.2)$ & $30(16.9)$ & $35(19.7)$ & $24(13.5)$ & $25(14.0)$ \\
\hline Thrombocytopenia & $6(14.0)$ & I (2.3) & $2(4.7)$ & $2(4.7)$ & $25(14.0)$ & $4(2.2)$ & $3(1.7)$ & $3(1.7)$ \\
\hline Bleeding & I (2.3) & $2(4.7)$ & 0 & 0 & $2(1.1)$ & $2(1.1)$ & 0 & 0 \\
\hline Febrile neutropenia & NA & NA & I (2.3) & I (2.3) & NA & NA & I (0.6) & I (0.6) \\
\hline Fatigue & $5(11.6)$ & $24(55.8)$ & $14(32.6)$ & 0 & $76(42.7)$ & $73(41.0)$ & $18(10.1)$ & 0 \\
\hline Anorexia & $16(37.2)$ & $18(41.9)$ & $6(14.0)$ & 0 & $79(44.4)$ & $41(23.0)$ & $8(4.5)$ & 0 \\
\hline Nausea & $14(32.6)$ & $18(41.9)$ & $7(16.3)$ & 0 & $67(37.6)$ & $55(30.9)$ & $8(4.5)$ & 0 \\
\hline Vomiting & $5(\mid 1.6)$ & $17(39.5)$ & $7(16.3)$ & 0 & $26(14.6)$ & $49(27.5)$ & $7(3.9)$ & 0 \\
\hline Stomatitis & $14(32.6)$ & $9(20.9)$ & 0 & 0 & $36(20.2)$ & $14(7.9)$ & 0 & 0 \\
\hline Constipation & $14(32.6)$ & $2(4.7)$ & 0 & 0 & $29(16.3)$ & $2(1.1)$ & 0 & 0 \\
\hline Diarrhoea & $24(55.8)$ & $10(23.3)$ & $3(7.0)$ & I (2.3) & $82(46.1)$ & $14(7.9)$ & $3(1.7)$ & I (0.6) \\
\hline Abdominal pain & $9(20.9)$ & $6(\mid 4.0)$ & 0 & 0 & $12(6.7)$ & $6(3.4)$ & 0 & 0 \\
\hline Transaminitis (ALT) & $9(20.9)$ & I (2.3) & $2(4.7)$ & 0 & $14(7.9)$ & $3(1.7)$ & 0 & 0 \\
\hline Transaminitis (AST) & $12(27.9)$ & $2(4.7)$ & I (2.3) & 0 & $22(12.4)$ & $3(1.7)$ & I (0.6) & 0 \\
\hline Hyperbilirubinemiaamia & I (2.3) & 0 & $2(4.7)$ & 0 & I (0.6) & I (0.6) & I (0.6) & 0 \\
\hline Cholinergic symptoms & $24(55.8)$ & $3(7.0)$ & 0 & 0 & $57(32.0)$ & $4(2.2)$ & 0 & 0 \\
\hline
\end{tabular}

Abbreviations: ALT = alanine transaminase; AST = aspartate transaminase; NA = not applicable. ${ }^{a}$ Toxicity evaluation was available for 178 cycles of chemotherapy. 
is consistent with that reported by a previous study of Asian populations. The frequency of the -40 insTA $\left({ }^{\star} 28\right)$ allele was 0.095 , and none of the enrolled patients were homozygous for the *28 allele.

\section{Association of UGT1A1 genotype with toxicity and irinotecan dose escalation}

The proteins encoded by UGT1A $1{ }^{*} 60,{ }^{*} 28$, and ${ }^{*} 6$ are known to possess different enzymatic activities. Thus, we categorised patients as having no defective alleles $(n=11)$, one defective allele $(n=15)$, or more than one defective allele $(n=14$; Table 5$)$. The results indicate that patients with no defective allele had a lower incidence of grade 3-4 neutropenia than other patients $(P=0.018$, Figure 2). Severe (grade 3 or worse) neutropenia developed more frequently in patients who were homozygous for the $-3279 \mathrm{~T}>\mathrm{G}$ allele 4 out of $4(100 \%)$ than in patients homozygous for the wildtype allele 7 out of $20(35 \%)$ or those who were heterozygous 6 out of $16(38 \%)$. Severe leukopenia and neutropenia was also more common in patients carrying UGT $1 \mathrm{~A} 1{ }^{\star} 6$ or ${ }^{\star} 28$.

\section{DISCUSSION}

Therapeutic options such as salvage chemotherapy are limited for patients with AGC. In this study, we evaluated individualised dosing of irinotecan monotherapy given every 3 weeks after failure with fluoropyrimidine, a platinum agent, and a taxane. We found that individualised dose optimisation produced an overall RR of $9.3 \%$, disease control rate of $62.8 \%$, and a tolerable toxicity profile.

Several phase II studies have evaluated irinotecan monotherapy as first-line chemotherapy for gastric cancer. In an European trial, Kohne et al (2003) administered irinotecan $\left(350 \mathrm{mg} \mathrm{m}^{-2}\right)$ every 3 weeks and reported an RR of $20 \%$. In a Japanese study, Futatsuki et al (1994) reported an RR of $23 \%$ in 60 evaluable patients who

Table 4 UGTIAI genotypes and allele frequencies

\begin{tabular}{|c|c|c|c|c|c|c|c|}
\hline UGTIAI & $\begin{array}{c}-3279 \\
\mathbf{T}>\mathbf{G}\end{array}$ & $\begin{array}{l}-364 \\
\mathrm{C}>\mathrm{T}\end{array}$ & $\begin{array}{l}-64 \\
\mathbf{G}>C\end{array}$ & $\begin{array}{c}-40-39 \\
\text { insTA }\end{array}$ & $\begin{array}{c}211 \\
\mathbf{G}>\mathbf{A}\end{array}$ & $\begin{array}{c}686 \\
C>A\end{array}$ & $\begin{array}{l}\mathbf{I} 456 \\
T>G\end{array}$ \\
\hline $\begin{array}{l}\text { Amino-acid } \\
\text { change }\end{array}$ & & & & & G7IR & P229Q & Y486D \\
\hline $\begin{array}{l}\text { Functional } \\
\text { change }\end{array}$ & Reduced & & & Reduced & Reduced & Reduced & Reduced \\
\hline $\begin{array}{l}\text { Marker } \\
\text { allele }\end{array}$ & $* 60$ & & & $* 28$ & *6 & $* 27$ & $* 7$ \\
\hline Frequency & 0.278 & 0.095 & 0.056 & 0.095 & 0.222 & 0.008 & 0.000 \\
\hline
\end{tabular}

received a dose of $100 \mathrm{mg} \mathrm{m}^{-2}$ every week or $150 \mathrm{mg} \mathrm{m}^{-2}$ every 2 weeks. As a second-line treatment for AGC, irinotecan produced a positive response in $16-20 \%$ of patients who did not respond to previous fluoropyrimidine or cisplatin-based chemotherapy (Futatsuki et al, 1994; Chun et al, 2004; Wesolowski et al, 2009). In this study, we observed an RR of $9.3 \%$ and TTP of 2.8 months, despite intensive previous treatment in our study population; 37 of the 43 enrolled patients (86\%) underwent second-line chemotherapy before enrolment. Although the RR and TTP in this study were modest, the OS associated with individualised dosing of irinotecan monotherapy appeared promising compared with results of previous trials. Asian studies assessing the efficacy of salvage regimens for metastatic gastric cancer have reported an RR of 6.7-23.1\%, TTP of 2.2-4.4 months, and OS of 6.2-10 months (Yoshida et al, 2006; Jeung et al, 2007; Jo et al, 2007; Lee et al, 2008; Shin et al, 2008; Sym et al, 2008; Zhong et al, 2008). We should be cautious when comparing these results because of differences in patient characteristics, inclusion/exclusion criteria, and further treatment after the clinical trial. For example, in this study all patients had a good performance status, and 28 of 43 patients (65.1\%) underwent further treatment with chemotherapy after stopping irinotecan chemotherapy. In this context, there could be a discrepancy between the short progression-free interval and longer survival after disease progression.

In this study, the most common haematological toxicity was grade $3-4$ granulocytopenia $(n=23,53.5 \%)$, and the least common

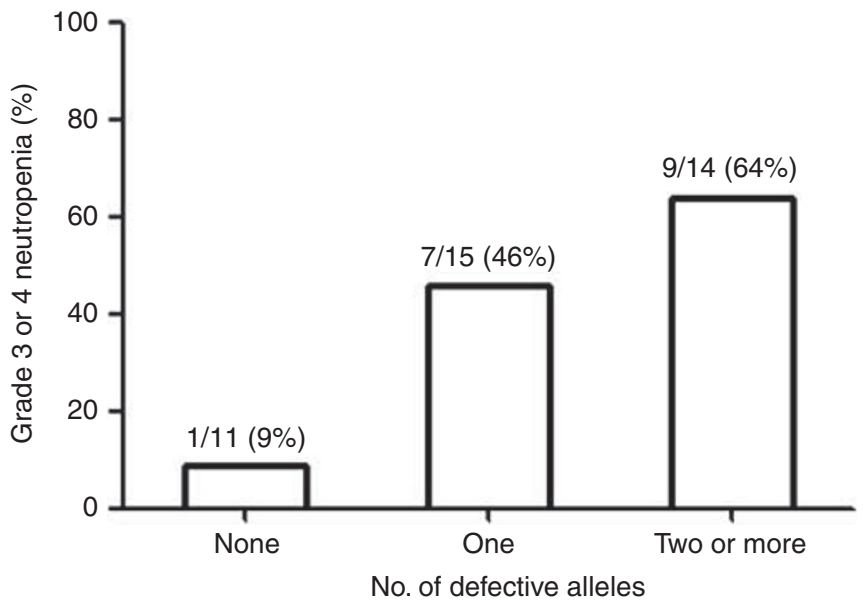

Figure 2 Number of defective alleles (*6, $* 28$, and $* 60$ ) and grade 3 or 4 neutropenia (\%) during the first cycle of irinotecan monotherapy $(n=40)$.

Table 5 Relationship between the number of defective alleles and toxicity $(n=40)$

\begin{tabular}{|c|c|c|c|c|c|c|}
\hline UGTIAI & $\begin{array}{l}\text { No. of defective } \\
\text { alleles }\end{array}$ & $\begin{array}{c}\text { No. of } \\
\text { patients }\end{array}$ & $\begin{array}{l}\text { Irinotecan dose } \\
\text { escalation }\end{array}$ & $\begin{array}{c}\text { Grade } 3-4 \\
\text { neutropenia }\end{array}$ & $\begin{array}{c}\text { Febrile } \\
\text { neutropenia }\end{array}$ & $\begin{array}{c}\text { Treatment } \\
\text { delay }\end{array}$ \\
\hline$*|/ *|$ & 0 & $\begin{array}{c}(n=\mid 1) \\
11 \\
(n=\mid 5)\end{array}$ & 4/II (36\%) & |/|| (9\%) & $0 / 11$ & $2 / 9(22 \%)$ \\
\hline$* 1 / * 60$ & I & 9 & $3 / 9(33 \%)$ & $3 / 9(33 \%)$ & $0 / 9$ & $4 / 9(44 \%)$ \\
\hline *1/*6 & I & $\begin{array}{c}6 \\
(n=14)\end{array}$ & $1 / 6(17 \%)$ & $4 / 6(67 \%)$ & $1 / 6(17 \%)$ & $2 / 5(40 \%)$ \\
\hline$* 6 / * 6$ & 2 & 4 & I/4 (25\%) & $2 / 4(50 \%)$ & $0 / 4$ & I/3 (33\%) \\
\hline$* 28 / * 60$ & 2 & 5 & I/5 (20\%) & $3 / 5(60 \%)$ & $0 / 5$ & I/5 (20\%) \\
\hline $\begin{array}{l}* 6 / * 28 / \\
* 60\end{array}$ & 3 & I & $0 / 1$ & I/I (I00\%) & $0 / 1$ & I/I (100\%) \\
\hline
\end{tabular}


toxicity was febrile neutropenia $(n=2,4.6 \%)$. The most common grade 3-4 non-haematological toxicities were fatigue $(32.6 \%)$, nausea $(16.3 \%)$, and vomiting $(16.3 \%)$. The frequency of grade $3-4$ granulocytopenia in our population $(53.5 \%)$ was higher than that reported by previous studies $(22-47 \%)$ that used standard irinotecan dosing (Futatsuki et al, 1994; Ychou et al, 2002; Van Cutsem et al, 2005). Few toxicities affecting the digestive system, such as severe diarrhoea (9.3\%), were observed in our study. This result was likely due to appropriate management of delayed diarrhoea (Duffour et al, 2003). The safety profile was acceptable despite dose escalation. In fact, the 10 patients who underwent dose escalation had rates of grade 3 or worse neutropenia, vomiting, and diarrhoea that were similar to those of the other patients.

A European phase I study that evaluated irinotecan administered once every 3 weeks to treat AGC reported higher RRs at higher doses (450-750 $\mathrm{mg} \mathrm{m}^{-2}$; Abigerges et al, 1995). Ychou et al (2002) administered an initial irinotecan dose of $350 \mathrm{mg} \mathrm{m}^{-2}$, increasing the dose to $500 \mathrm{mg} \mathrm{m}^{-2}$ in subsequent cycles for patients without grade 2 or worse non-haematological toxicities. In that study, the increased dose given to $63 \%$ of patients in the firstline setting was associated with increased activity. The RR was $35.5 \%$ for patients who received the high dose and $24.5 \%$ for patients who received the low dose. Van Cutsem et al (2005) reported that individualised dose escalation of irinotecan (up to $500 \mathrm{mg} \mathrm{m}^{-2}$ based on patient tolerance) allowed more patients to receive higher doses without increased toxicity. This study demonstrated that individualised dose escalation based on toxicity in the preceding cycle could be a feasible salvage strategy for treating AGC. In addition, the RR and disease control rate in this study were similar to those obtained with standard dosing of irinotecan in a second-line setting (Futatsuki et al, 1994; Chun et al, 2004; Wesolowski et al, 2009) and irinotecan-based combination chemotherapy as salvage treatment (Sym et al, 2008).

\section{REFERENCES}

Abigerges D, Chabot GG, Armand JP, Herait P, Gouyette A, Gandia D (1995) Phase I and pharmacologic studies of the camptothecin analog irinotecan administered every 3 weeks in cancer patients. J Clin Oncol 13(1): 210-221

Ando Y, Saka H, Ando M, Sawa T, Muro K, Ueoka H, Yokoyama A, Saitoh S, Shimokata K, Hasegawa Y (2000) Polymorphisms of UDP-glucuronosyltransferase gene and irinotecan toxicity: a pharmacogenetic analysis. Cancer Res 60(24): 6921-6926

Chun JH, Kim HK, Lee JS, Choi JY, Lee HG, Yoon SM, Choi IJ, Ryu KW, Kim Y-W, Bae J-M (2004) Weekly irinotecan in patients with metastatic gastric cancer failing cisplatin-based chemotherapy. Jpn J Clin Oncol 34(1): 8-13

Cunningham D, Starling N, Rao S, Iveson T, Nicolson M, Coxon F, Middleton G, Daniel F, Oates J, Norman AR (2008) Capecitabine and oxaliplatin for advanced esophagogastric cancer. $N$ Engl J Med 358(1): 36-46

Duffour J, Gourgou S, Seitz JF, Senesse P, Boutet O, Castera D, Kramar A, Ychou M (2003) Efficacy of prophylactic anti-diarrhoeal treatment in patients receiving Campto for advanced colorectal cancer. Anticancer Res 22(6B): 3727-3731

Futatsuki K, Wakui A, Nakao I, Sakata Y, Kambe M, Shimada Y, Yoshino M, Taguchi T, Ogawa N (1994) Late phase II study of irinotecan hydrochloride (CPT-11) in advanced gastric cancer. CPT-11 Gastrointestinal Cancer Study Group. Gan To Kagaku Ryoho 21(7): 1033-1038

Glimelius B, Ekstrom K, Hoffman K, Graf W, Sjoden PO, Haglund U, Svensson C, Enander LK, Linne T, Sellstrom H, Heuman R (1997) Randomized comparison between chemotherapy plus best supportive care with best supportive care in advanced gastric cancer. Ann Oncol 8(2): 163-168

Gupta E, Lestingi TM, Mick R, Ramirez J, Vokes EE, Ratain MJ (1994) Metabolic fate of irinotecan in humans: correlation of glucuronidation with diarrhea. Cancer Res 54(14): 3723-3725

Iyer L, King CD, Whitington PF, Green MD, Roy SK, Tephly TR Coffman BL, Ratain MJ (1998) Genetic predisposition to the metabolism
Pharmacogenetic features, such as UGT1A1 profile, are believed to have an important role in the highly variable toxicity to irinotecan (Ando et al, 2000). Among UGT1A1 genotypes, ${ }^{\star} 60$ is common in Asian populations, as seen in this study. In Caucasian populations, allele frequencies have been reported as 0.550 for ${ }^{\star} 60$, 0.388 for ${ }^{\star} 28$, and 0.007 for ${ }^{\star} 6$ (Kaniwa et al, 2005). We found that the number of UGT1A1 defective alleles was associated with the severity of neutropenia. The clinical implications of this finding are limited, because severe neutropenia did not result in febrile neutropenia or treatment delay. However, our study may provide information about the influence of UGT1A1 genotype on the severity of neutropenia.

In conclusion, our study demonstrated the safety of individualised irinotecan dose escalation based on patient tolerance. In addition, the modest anticancer activity of irinotecan indicates its feasibility as salvage chemotherapy for AGC after failure of previous treatment with fluoropyrimidine, a platinum drug, and a taxane. UGT1A1 genotyping may be a useful tool to identify the most appropriate starting dose.

\section{ACKNOWLEDGEMENTS}

This study was supported by a grant from the Korea Health 21 R\&D Project, Ministry of Health \& Welfare and Family Affairs, R.O.K. (A030001) and a grant (2006-231) from the Asan Institute for Life Science, Seoul, Korea.

\section{Conflict of interest}

The authors declare no conflict of interest. of irinotecan (CPT-11). Role of uridine diphosphate glucuronosyltransferase isoform $1 \mathrm{~A} 1$ in the glucuronidation of its active metabolite (SN-38) in human liver microsomes. J Clin Invest 101(4): 847-854

Jeung HC, Rha SY, Shin SJ, Ahn JB, Noh SH, Roh JK, Chung HC (2007) A phase II study of S-1 monotherapy administered for 2 weeks of a 3-week cycle in advanced gastric cancer patients with poor performance status. Br J Cancer 97(4): 458-463

Jo JC, Lee JL, Ryu MH, Sym SJ, Lee SS, Chang HM, Kim TW, Lee JS Kang YK (2007) Docetaxel monotherapy as a second-line treatment after failure of fluoropyrimidine and platinum in advanced gastric cancer: experience of 154 patients with prognostic factor analysis. Jpn J Clin Oncol 37(12): 936-941

Kang YK, Kang WK, Shin DB, Chen J, Xiong J, Wang J, Lichinitser M Guan Z, Khasanov R, Zheng L, Philco-Salas M, Suarez T, Santamaria J, Forster G, McCloud PI (2009) Capecitabine/cisplatin versus 5-fluorouracil/cisplatin as first-line therapy in patients with advanced gastric cancer: a randomised phase III noninferiority trial. Ann Oncol 20(4): 666-673

Kang YK, Ryu MH, Yoo C, Chang HM, Yook JH, Oh ST, Kim BS, Kim TW (2011) Phase I/II study of a combination of docetaxel, capecitabine, and cisplatin (DXP) as first-line chemotherapy in patients with advanced gastric cancer. Cancer Chemother Pharmacol 67(6): 1435-1443

Kang YK, Yoon DH, Ryoo BY, Ryu MH (2010) Recent advances in chemotherapy for advanced gastric cancer. Asia-Pacific J Oncol \& Hematol 2(1): 67-74

Kaniwa N, Kurose K, Jinno H, Tanaka-Kagawa T, Saito Y, Saeki M, Sawada J, Tohkin M, Hasegawa R (2005) Racial variability in haplotype frequencies of UGT1A1 and glucuronidation activity of a novel single nucleotide polymorphism $686 \mathrm{C}>\mathrm{T}$ (P229L) found in an AfricanAmerican. Drug Metab Dispos 33(3): 458-465

Ki CS, Lee KA, Lee SY, Kim HJ, Cho SS, Park JH, Cho S, Sohn KM, Kim JW (2003) Haplotype structure of the UDP-glucuronosyltransferase 1A1 (UGT1A1) gene and its relationship to serum total bilirubin concentration in a male Korean population. Clin Chem 49(12): 2078-2081 
Kim NK, Park YS, Heo DS, Suh C, Kim SY, Park KC, Kang YK, Shin DB, Kim HT, Kim HJ (1993) A phase III randomized study of 5-fluorouracil and cisplatin versus 5 -fluorouracil, doxorubicin, and mitomycin $\mathrm{C}$ versus 5 -fluorouracil alone in the treatment of advanced gastric cancer. Cancer 71(12): 3813-3818

Kim TW, Kang YK, Ahn JH, Chang HM, Yook JH, Oh ST, Kim BS, Lee JS (2002) Phase II study of capecitabine plus cisplatin as first-line chemotherapy in advanced gastric cancer. Ann Oncol 13(12): 1893-1898

Kohne CH, Catane R, Klein B, Ducreux M, Thuss-Patience P, Niederle N, Gips M, Preusser P, Knuth A, Clemens M, Bugat R, Figer I, Shani A, Fages B, Di Betta D, Jacques C, Wilke HJ (2003) Irinotecan is active in chemonaive patients with metastatic gastric cancer: a phase II multicentric trial. Br J Cancer 89(6): 997-1001

Koizumi W, Tanabe S, Saigenji K, Ohtsu A, Boku N, Nagashima F, Shirao K, Matsumura Y, Gotoh M (2003) Phase I/II study of S-1 combined with cisplatin in patients with advanced gastric cancer. $\mathrm{Br} J$ Cancer 89: 2207-2212

Lee JL, Ryu MH, Chang HM, Kim TW, Yook JH, Oh ST, Kim BS, Kim M, Chun YJ, Lee JS, Kang YK (2008) A phase II study of docetaxel as salvage chemotherapy in advanced gastric cancer after failure of fluoropyrimidine and platinum combination chemotherapy. Cancer Chemother Pharmacol 61(4): 631-637

Murad AM, Santiago FF, Petroianu A, Rocha PR, Rodrigues MA, Rausch M (1993) Modified therapy with 5-fluorouracil, doxorubicin, and methotrexate in advanced gastric cancer. Cancer 72(1): 37-41

Parkin DM, Bray F, Ferlay J, Pisani P (2005) Global Cancer Statistics, 2002. CA Cancer J Clin 55(2): 74-108

Pyrhonen S, Kuitunen T, Nyandoto P, Kouri M (1995) Randomised comparison of fluorouracil, epidoxorubicin and methotrexate (FEMTX) plus supportive care with supportive care alone in patients with nonresectable gastric cancer. Br J Cancer 71(3): 587-591

Shin SJ, Jeung HC, Ahn JB, Choi HJ, Cho BC, Rha SY, Yoo NC, Roh JK, Chung HC (2008) Capecitabine and doxorubicin combination chemotherapy as salvage therapy in pretreated advanced gastric cancer. Cancer Chemother Pharmacol 61(1): 157-165

Sym SJ, Ryu MH, Lee JL, Chang HM, Kim TW, Lee SS, Lee JS, Kang YK (2008) Salvage chemotherapy with biweekly irinotecan, plus 5-fluorouracil and leucovorin in patients with advanced gastric cancer previously treated with fluoropyrimidine, platinum, and taxane. Am J Clin Oncol 31(2): 151-156

Van Cutsem E, Dirix L, Van Laethem JL, Van Belle S, Borner M, Gonzalez Baron M, Roth A, Morant R, Joosens E, Gruia G, Sibaud D, Bleiberg H (2005) Optimisation of irinotecan dose in the treatment of patients with metastatic colorectal cancer after 5-FU failure: results from a multinational, randomised phase II study. Br J Cancer 92(6): 1055-1062

Vanhoefer U, Rougier P, Wilke H, Ducreux MP, Lacave AJ, Van Cutsem E, Planker M, Santos JGD, Piedbois P, Paillot B, Bodenstein H, Schmoll H-J, Bleiberg H, Nordlinger B, Couvreur M-L, Baron B, Wils JA (2000) Final results of a randomized phase III trial of sequential high-dose methotrexate, fluorouracil, and doxorubicin versus etoposide, leucovorin, and fluorouracil versus infusional fluorouracil and cisplatin in advanced gastric cancer: a trial of the European Organization for Research and Treatment of Cancer Gastrointestinal Tract Cancer Cooperative Group. J Clin Oncol 18(14): 2648-2657

Webb A, Cunningham D, Scarffe JH, Harper P, Norman A, Joffe JK Hughes M, Mansi J, Findlay M, Hill A, Oates J, Nicolson M, Hickish T, O'Brien M, Iveson T, Watson M, Underhill C, Wardley A, Meehan M (1997) Randomized trial comparing epirubicin, cisplatin, and fluorouracil versus fluorouracil, doxorubicin, and methotrexate in advanced esophagogastric cancer. J Clin Oncol 15(1): 261-267

Wesolowski R, Lee C, Kim R (2009) Is there a role for second-line chemotherapy in advanced gastric cancer? Lancet Oncol 10(9): 903-912

Ychou M, Raoul JL, Desseigne F, Borel C, Caroli-Bosc FX, Jacob JH, Seitz JF, Kramar A, Hua A, Lefebvre P, Couteau C, Merrouche Y (2002) High-dose, single-agent irinotecan as first-line therapy in the treatment of metastatic colorectal cancer. Cancer Chemother Pharmacol 50(5): 383-391

Yoshida T, Yoshikawa T, Tsuburaya A, Kobayashi O, Hasegawa S Osaragi T, Sairenji M (2006) Feasibility study of biweekly CPT-11 plus CDDP for S-1- and paclitaxel-refractory, metastatic gastric cancer. Anticancer Res 26(2B): 1595-1598

Zhong H, Zhang Y, Ma S, Ying JE, Yang Y, Yong D, Hang X, Sun Q, Zhong B, Wang D (2008) Docetaxel plus oxaliplatin (DOCOX) as a second-line treatment after failure of fluoropyrimidine and platinum in Chinese patients with advanced gastric cancer. Anticancer Drugs 19(10): $1013-1018$

This work is published under the standard license to publish agreement. After 12 months the work will become freely available and the license terms will switch to a Creative Commons Attribution-NonCommercial-Share Alike 3.0 Unported License. 